\title{
Testing potential psychological predictors of attitudes towards cultured meat
}

Matti Wilks ${ }^{1}$, Clive J. C. Phillips ${ }^{2}$, Kelly Fielding ${ }^{3}$, Matthew J. Hornsey ${ }^{4}$

1. Department of Psychology, Yale University, New Haven, United States

2. Centre for Animal Welfare and Ethics, School of Veterinary Science, University of Queensland, Gatton, Australia

3. School of Communication and Arts, University of Queensland, Brisbane, Australia

4. UQ Business School, University of Queensland, Brisbane, Australia

Author for correspondence: matti.wilks@yale.edu

Department of Psychology, Kirtland Hall

2 Hillhouse Avenue, New Haven, CT, 06511

\section{Acknowledgments}

Thank you to Hannibal Thai for his assistance with data collection. 


\begin{abstract}
Cultured meat is an emerging food technology that has the potential to resolve many of the social, environmental and ethical issues surrounding traditional factory farming practices. Recently, research has begun to explore consumer attitudes to the product, revealing a number of barriers and demographic predictors. However, our understanding of the psychological mechanisms that underpin attitudes to cultured meat remains limited. In the current study, we draw on an attitude roots model (Hornsey \& Fielding, 2017) to explore a range of psychological mechanisms that may underpin attitudes to cultured meat. In terms of negative attitudes and intentions toward cultured meat, the most powerful predictors were food neophobia, political conservatism, and distrust of food scientists. When it comes to absolute opposition to cultured meat - defined by the unconditional belief that it should never be allowed under any circumstances - the strongest predictors were food and hygiene disgust sensitivity subscales, food neophobia, and conspiratorial ideation. A number of presumed mechanisms held no relationships to cultured meat attitudes, including social dominance orientation, speciesism, and naturalness bias. The null results on naturalness bias are of particular interest given recent research identifying concerns about naturalness as a key barrier to consumer acceptance. These results demonstrate the need for a more nuanced understanding of the psychological mechanisms that contribute to cultured meat attitudes and engagement.
\end{abstract}




\section{The psychological roots of attitudes towards cultured meat}

There is increasing awareness of the social, environmental and ethical issues surrounding traditional meat production (Martin, Thottathil, \& Newman, 2015; Petrovic, Djordjevic, Milicevic, Nastasijevic, \& Parunovic, 2015; Singer, 1981; Walker, Rhubart-Berg, McKenzie, Kelling, \& Lawrence, 2005). Despite this, our appetite for meat remains strong, and world meat production is expected to continue to increase (Food and Agriculture Organization of the United Nations, 2017). In light of these issues, there is a clear need for a new meat production method that circumvents concerns surrounding farmed meat practices. Cultured meat, also known as 'in-vitro' or 'clean meat', provides one potential option. In production, cells are removed from an animal, fed, and grown externally from the donor animal, resulting in a meat product that does not require large-scale farming practices (Post, 2014a, 2014b).

Of course, technological advances in the production of cultured meat will amount to little if there is consumer resistance to eating it: consumer acceptance is critical for the success of any new food technology. Recent qualitative and quantitative research in psychology and related fields have revealed mixed attitudes to cultured meat. Levels of acceptance vary widely, with estimates ranging from around 25\%-65\% of samples reporting willingness to eat cultured meat (Verbeke, Sans, \& Van Loo, 2015; Wilks \& Phillips, 2017). Qualitative research has identified a number of positive themes related to cultured meat, including potential environmental and public health benefits (Laestadius \& Caldwell, 2015; Marcu et al., 2015; Verbeke, Marcu, et al., 2015). However, negative themes have also been identified including concerns around genetic modification, questions relating to the definition of "real" meat, concerns about "playing god", and social concerns about loss of an agricultural industry (Laestadius \& Caldwell, 2015; Verbeke, Marcu, et al., 2015). 
Quantitative data mirror this pattern. Participants identify positive environmental and ethical benefits, including reducing waste, reducing environmental impacts of farmed meat, and improved animal welfare (Tucker, 2014; Verbeke, Sans, et al., 2015; Wilks \& Phillips, 2017). Negative perceptions focus more on personal concerns such as taste, appeal, price, and (un)naturalness (Verbeke, Sans, et al., 2015; Wilks \& Phillips, 2017). Some demographic factors have also been implicated, with more negative attitudes among conservatives (Wilks \& Phillips, 2017), older people (Tucker, 2014), women (Tucker, 2014; Wilks \& Phillips, 2017), poorer (Tucker, 2014), rural (Tucker, 2014), and less educated respondents (Hocquette et al., 2015). Additionally, vegetarian and vegan respondents report less willingness to try cultured meat than meat eaters, although they are also more likely to recognize its benefits (Wilks, 2018).

To date, the focus on demographic and pragmatic factors means that there is not yet a detailed understanding of the psychological factors that may underpin attitudes to cultured meat. This limits our ability to create targeted interventions that could fully engage people with the idea of eating cultured meat.

The current study aims to provide a more comprehensive account of the psychological factors predicting attitudes and behavioral intentions toward cultured meat. In doing so, we draw on the "attitude roots" model proposed by Hornsey and Fielding (2017), which was designed to understand why people might resist scientific innovations and understandings. This model uses a tree metaphor, in which the part of the tree that lies above the surface represents people's "surface attitudes"; the attitudes that people declare to others about scientific issues such as cultured meat. Underneath the ground are the "attitude roots", which are the underlying motivations that form and sustain the surface attitudes. According to the model, it is the attitude roots that makes people want to reject a scientific innovation, and which causes the attitude holder to process the evidence and arguments around the issue in a biased way. The 
authors identify a number of broad attitude roots, of which we examine three that theoretically could be explanatory mechanisms for understanding attitudes toward cultured meat: conspiratorial ideation, fears/phobias, and worldviews. Each is discussed below.

\section{Conspiratorial Ideation}

Conspiratorial ideation refers to a general predisposition to believe that conspiracies happen; that it is commonplace for networks of people with malevolent intentions to work in secret to execute plots and hoaxes on the public (Wood, Douglas, \& Sutton, 2012, 2017). This cognitive frame is correlated with a number of anti-science attitudes, including the belief that the health risks of vaccinations are downplayed (Hornsey, Harris, \& Fielding, 2018b) and (in U.S. samples at least) that climate scientists are motivated to fabricate or exaggerate claims about climate change for their own benefit (Hornsey, Harris, \& Fielding, 2018a; Lewandowsky, Gignac, \& Oberauer, 2015; Lewandowsky, Oberauer, \& Gignac, 2013). In the current study, we test whether this relationship between conspiratorial thinking and science skepticism also carries over into perceptions of cultured meat. Although we cannot point to any research that has highlighted a specific conspiracy that applies to cultured meat, it shares elements in common with other issues that have been prone to conspiracy-based skepticism. Specifically, it is a new and largely untested innovation, the benefits of which are largely communicated by people who are perceived to also stand to profit from its uptake.

\section{Fears and Phobias}

Hornsey and Fielding (2017) argue that resistance toward scientific innovations sometimes emerge because they arouse clinical or sub-clinical fears and phobias. For example, people who have disgust reactions to images of blood and needles might be motivated to organize and legitimize their avoidant response under the guise of an anti-vaccination philosophy (Hornsey et al., 2018b). It is possible that a similar process could emerge with 
regard to cultured meat: that people will feel fear or experience a disgust response that makes it difficult to embrace cultured meat, regardless of its objective costs and benefits. In the current study we tap into this possibility using two measures: food neophobia and disgust sensitivity.

Food neophobia describes an individual's fear of new foods. Several studies have measured and documented food neophobia in humans (Demattè, Endrizzi, \& Gasperi, 2014; Pliner \& Hobden, 1992; Raudenbush, Schroth, Reilley, \& Frank, 1998; Tuorila, Meiselman, Bell, Cardello, \& Johnson, 1994). As a food technology which is not yet available, cultured meat is a prototypical "new food" and so it seems plausible that general food neophobia may result in negative attitudes to cultured meat. Moreover, one study has found that food neophobia negatively predicted willingness to try plant-based meat substitutes $\mathrm{h}($ Hoek et al., 2011).

Disgust sensitivity refers to people's general predisposition to have reactions of disgust to various stimuli. There are major individual differences in trait disgust sensitivity (Haidt, McCauley, \& Rozin, 1994), which are predictive of a range of behaviors including food preferences (Ammann, Hartmann, \& Siegrist, 2017). Moreover, trait disgust sensitivity is positively related to meat avoidance (Fessler, Arguello, Mekdara, \& Macias, 2003), (lack of) appeal is often cited as a barrier to cultured meat, and state disgust is often identified as a concern in qualitative studies of perceptions of cultured meat (Verbeke, Marcu, et al., 2015)

\section{Worldviews}

The term "worldviews" is used here to refer to a particular conception of the world or philosophy about the way the world should be (this includes ideologies). Focusing on worldviews as drivers of risk perceptions has a long history, tracing back to the work of Mary Douglas (a social anthropologist) and Aaron Wildavsky (a political scientist) who made the argument that perceptions of risk were not necessarily built upon individual psychological 
processes but rather by cultural processes (Douglas \& Wildavsky, 1982). According to this argument, the world is so complex and dangerous that individuals cannot appraise all the risks that they face. Instead, individuals have to choose a handful of risks on which to focus and become a target for their anxieties. These choices are not made randomly or indiscriminately; rather, people choose to focus on the risks associated with things that they already oppose based on their political and moral affiliations. Later, a group of interdisciplinary scholars adapted these ideas to theorize a cultural cognition of risk. Members of the cultural cognition project (e.g., Kahan, Braman, Cohen, Gastil, \& Slovic, 2010) argued that cultural orientations shape people's appraisal of risk, evidence, and scientific consensus. For example, people who subscribe to relatively individualistic and hierarchical values are more inclined to value industry and so are motivated to disbelieve that industry poses a risk to the environment. In contrast, people who subscribe to relatively egalitarian and communitarian values are more likely to have a moral suspicion of industry, and so are motivated to embrace the risk that industry presents to the environment (Kahan, 2010). Drawing on this theory, Hornsey and Fielding (2017) elaborated on the different ways in which people interpret science through the lens of their worldviews, in a way that sometimes leads to biased appraisals of evidence. In the current paper we examine five worldviews: political conservatism, naturalness bias, speciesism, social dominance orientation, and distrust of science. We elaborate on these constructs below.

Political conservatism. A previous study has found that conservatives tend to hold less positive attitudes to cultured meat, and are also less willing to engage with it (Wilks \& Phillips, 2017). Although the underlying reasons for this have not been established, it is worth noting that conservatism has previously been linked with hesitancy towards other trust-sensitive scientific arguments, such as those making the case for anthropogenic climate change 
(Hornsey et al., 2018a; Hornsey, Harris, Bain, \& Fielding, 2016) and vaccinations (Rabinowitz, Latella, Stern, \& Jost, 2016; Hornsey et al., 2018b).

Naturalness bias. Naturalness bias refers to preference for things that are natural. Research suggests that, generally, perceptions of naturalness are heightened when additive, rather than subtractive, processes occur, which might be linked to higher perceptions of contamination (Scott \& Rozin, 2017). Consistent with this, several past studies have identified naturalness bias as a major factor predicting people's concern about food additives (Scott \& Rozin, 2017) and genetically modified foods (Scott, Inbar, \& Rozin, 2016). In the context of cultured meat, both qualitative and correlational studies have linked resistance to cultured meat with concerns about its perceived unnaturalness (Laestadius \& Caldwell, 2015; Siegrist \& Sütterlin, 2017; Siegrist, Sütterlin, \& Hartmann, 2018). Furthermore, Siegrist and colleagues (2018) found that providing further information about the process of developing cultured meat increased support for farmed meat, in part because of concerns about naturalness of the process. In the current study we examine preference for the natural as a broad worldview, and examine whether this "naturalness bias" is a predictor of attitudes and intentions toward cultured meat.

Speciesism. Speciesism refers to the belief that humans hold higher moral worth than other animals. Past research has identified the existence of speciesism (Dhont, Hodson, Costello, \& MacInnis, 2014; Piazza et al., 2015) and linked such attitudes to prejudice, social dominance orientation (Dhont \& Hodson, 2014), higher meat consumption, and lower concern for animals (Piazza et al., 2015). The recent development and validation of a speciesism scale (Caviola, Everett, \& Faber, 2018) has further identified this construct as a stable and unique predictor of racism, sexism and homophobia, as well as people's prosociality towards animals, including their dietary choices (Caviola et al., 2018). This suggests that people with more speciesist attitudes may hold fewer concerns about the treatment of animals in traditional 
farming practices, and so see less need for cultured meat; either because they hold less concern for animals generally, or because they see meat production as justified given humans' superior status to animals.

Social dominance orientation (SDO). SDO refers to the degree that one values equality among social groups, where higher SDO indicates greater support for unequal status between groups. Research shows that those in positions of power are more likely to be high in SDO (Pratto, Sidanius, Stallworth, \& Malle, 1994). Moreover, SDO has been linked to increased racism and belief in meritocracies. Of more relevance to the current paper, it has been argued that those high in SDO also perceive a hegemony in which humans have superiority over the natural world; consistent with this, SDO is positively correlated with speciesism (Caviola et al., 2018) and negatively correlated with pro-environmental behavior (Milfont, Richter, Sibley, Wilson, \& Fischer, 2013). This suggests that, similar to speciesism, those high in SDO may feel that current meat production is justified given humans' superior status to animals, and so see less need for cultured meat.

Distrust in science. Distrust in science refers to people's general attitudes about the trustworthiness of scientists. Research has identified distrust in science as a predictor of negative attitudes to genetically modified food and stem cell research (Critchley, 2008; Gaskell, 1999), suggesting that it may also predict negative attitudes to cultured meat, a food that is the outcome of a scientific process.

\section{The current study}

Identifying the relationships between these constructs and attitudes to cultured meat will provide insight into the psychological mechanisms that may underlie resistance.

Developing a thorough understanding of the psychological barriers toward embracing cultured meat helps lay the theoretical foundation from which it might be possible to develop nuanced 
engagement techniques to overcome these barriers. With a view to this, we conducted an online survey measuring each of the aforementioned constructs, as well as attitudes and behavioral intentions toward cultured meat. The link between conservatism and cultured meat has been established previously (Wilks \& Phillips, 2017) and so this prediction is simply a replication attempt. Similarly, there is evidence that resistance to cultured meat is positively correlated with a tendency to find it "disgusting" (Siegrist et al., 2018), though no research has directly explored disgust sensitivity as a predictor.

Other relationships have not been tested before, but predictions can be extrapolated from previous insights. For example, the prediction that negativity toward cultured meat would be associated with food neophobia is extrapolated from prior work identifying that food neophobia was negatively related to willingness to consume meat substitutes (Hoek et al., 2011). Furthermore, although no-one has previously tested whether a general preference for natural things predicts attitudes and intentions to cultured meat, this seems sensible given previous correlational findings that negativity to cultured meat is associated with perceptions of its unnaturalness (Siegrist \& Sütterlin, 2017; Siegrist et al., 2018). The predicted links between SDO, speciesism, and negativity toward cultured meat are based on the (as yet untested) assumption that concern for animal welfare will predispose people to embrace ethical alternatives to traditional farmed meat. Finally, given the hesitation around science and new technology associated with conspiratorial ideation and distrust in science, we predict that these variables will also negatively predict attitudes to cultured meat.

Outcome measures were assessed in three ways: willingness to eat cultured meat, perceptions of benefits of cultured meat (relative to farmed meat), and "absolute" opposition to cultured meat. The first two operationalizations are consistent with previous studies examining attitudes and behavioral intentions toward cultured meat. The last construct refers to attitudes that are of an absolute nature (Scott et al., 2016) defined by unconditional proscription (i.e., the 
notion that it should never be allowed under any circumstances; Baron \& Spranca, 1997). Due to the exploratory nature of the study, we did not make explicit predictions about whether the predictors would have different relationships for each unique outcome variable.

\section{Method}

This study was conducted in December 2017. Participants were community members recruited through the online data collection company Social Sampling International. The participant information, consent and questionnaire were all hosted and administered on the online Qualtrics platform. Participants were required to be 18 years or older and living in the U.S. to participate. Participants first responded to a series of scales measuring the psychological and ideological variables described above. They were then introduced to the concept of cultured meat via a short description (below), and finally were asked their opinions about cultured meat.

"Cultured meat is an animal flesh product that has never been part of a living animal, but is instead grown in a laboratory using muscle stem cells. These stem cells are extracted without suffering to the animal. Cultured meat is also referred to as clean meat, or in vitro meat.

In August 2013, scientists unveiled (and tasted) the world's first cultured hamburger patty. Currently it is not commercially available, though research is being conducted to introduce it as a potential new meat production technique in the future."

\section{Participants}

A total of 1327 respondents started the survey. Of these, 134 failed an attention check ("To show that you are paying attention, please select option 'Slightly Agree"”). We removed those who failed the attention check from analyses, leaving a final sample of 1193 participants. 
The demographic characteristics of the sample are summarized in Table 1, and compared to the demographic characteristics of the U.S. population (Bureau, 2016; Gallup Inc, 2012, 2017; Statista.com, 2015). As can be seen, our sample approximated representativeness in terms of income and the percentage of meat-eaters, but our respondents were more highly educated than the U.S. population. The fact that our sample is somewhat older than the U.S. national data may be partly or wholly attributable to the fact that respondents needed to be 18 or over to complete the survey. The sample also slightly over-represented males. Importantly, however, all analyses reported in this paper were conducted after controlling for demographics. Data are available on the Open Science Framework.

Table 1.

Demographics of current sample compared to U.S. National Data.

U.S. National Data

Current Data

Age (median, years)

37.8

47.0

Gender (\% male)

$49.2 \%$

$56.8 \%$

Household income (Median USD)

55,322

$40,000-59,000$

\section{Education}

High school graduate above

$87.0 \%$

$97.2 \%$

Bachelor's degree or above

$30.3 \%$

$46.3 \%$

\section{Meat Consumption}

Do not consume any meat 


\section{Materials}

Political conservatism was measured using a single item asking people to rate which set of ideas most closely suited their opinions on a scale from $1=$ Liberal to $9=$ Conservative.

Naturalness bias was measured using a scale developed for the current experiment. Participants were asked to express their agreement with eight questions, using a scale from $1=$ strongly disagree to $7=$ strongly agree. The scale was created by taking the mean of the eight items with higher scores representing greater preference for naturalness. The questions were: (1) More often than not, human intervention causes damage to nature; (2) The impact of humans on nature is often more serious and wide-ranging than people expect; (3) Natural things tend to be healthier than non-natural things; (4) Natural medicine is more effective than medicine made in a lab; (5) Natural food tastes better than processed food; (6) Natural food is safer than processed food; (7) Natural medicine is safer than medicine made in a lab; (8) Things that are natural are inherently better than things that are not natural. We conducted an exploratory factor analysis with promax rotation to examine the validity of the scale. The Kaiser-Meyer Olkin measure was .85 , and Bartlett's test of sphericity was significant ( $p<$ .001), indicating that the sample was adequate for factor analysis. All eight items showed medium to high correlations $(>.54)$. There was a large drop between the size of the first factor that was extracted (eigenvalue $=4.16,52.02 \%$ variance explained) and the second factor (eigenvalue $=1.14,14.26 \%$ variance explained $).$ Based on the scree test, then, we chose a single-factor solution. It should also be noted that the 2-factor solution was not easily interpretable, with unacceptably high cross-loadings across the factors for half the items (>.40). The final 8-item scale proved to have high internal reliability $(\alpha=.87)$.

Speciesism was measured using a scale developed by Caviola and colleagues (2018). Respondents expressed their agreement with six statements, including "Morally, animals 
always count for less than humans" and "It is morally acceptable to keep animals in circuses for human entertainment" ( 1 = strongly disagree to 7 strongly agree). The mean of the six items formed a reliable scale $(\alpha=.80)$ with higher scores representing greater belief in the moral superiority of humans over animals.

SDO was measured using the 8-item $\mathrm{SDO}_{7}$ developed by Ho and colleagues (2015). Participants responded to eight statements (e.g., "Some groups of people are simply inferior to others" and "An ideal society requires some people to be on the top and others to be on the bottom") on a scale from $1=$ strongly oppose to $7=$ strongly favor. The mean of the eight items formed a reliable scale $(\alpha=.77)$ with higher scores representing greater social dominance orientation.

Distrust in science was measured using four items from Frewer, Scholderer, and Bredahl (2003), but adapted to refer specifically to food scientists. Participants responded to four statements (e.g. "Scientists are likely to withhold information about food-related issues from the public" and "Information about food-related hazards from scientists is distorted") on a scale from $1=$ strongly disagree to $7=$ strongly agree. The mean of the four items formed a scale where higher scores represent greater distrust $(\alpha=.77)$.

Conspiratorial ideation was measured using four items from a scale developed by Lewandowsky, Oberauer, and Gignac (2013). Participants indicated their agreement with four conspiracies: "A powerful and secret group known as the New World Order are planning to eventually rule the world through an autonomous government, which would replace sovereign governments"; "The assassination of John F Kennedy was not committed by the lone gunman Lee Harvey Oswald, but rather was a detailed and organized conspiracy to kill the president"; “Princess Diana's death was not an accident but rather an organisation assassination by members of the British royal family, who disliked her"; and "The U.S. Government allowed 
the 9-11 attacks to take place so that it would have an excuse to achieve foreign and domestic goals that had been determined prior to the attacks". Responses were recorded on a scale from $1=$ strongly disagree to $5=$ strongly agree, with a sixth "I don't know" option (these responses were excluded). The four items correlated highly and formed a reliable scale $(\alpha=.81)$.

Food neophobia was measured using a scale developed by Pilner and Hobden (1992). Participants were asked to express their agreement with ten questions, including "Ethnic foods look too weird to eat" and "I am constantly sampling new and different foods" (reversed; $1=$ strongly disagree to $7=$ strongly agree $)$. The mean of the 10 items formed a reliable scale $(\alpha=$ .89) with higher scores indicating a stronger phobia towards new foods.

Disgust sensitivity was measured using items from two subscales of the full scale developed by Haidt, McCauley, and Rozin (1994) and adapted by Olatunji and colleagues (2007). We limited our choice to two subscales - food and hygiene - to ensure that participants were not fatigued by responding to a large battery of questions. These particular subscales were chosen because they were most relevant to attitudes to cultured meat - food as directly relevant to consumption, and hygiene as relevant through potential for food contamination. Participants were asked to state how true four statements were about them, including "I never let any part of my body touch the toilet seat in restrooms" and "I would probably not go to my favorite restaurant if I found out the cook had a cold" $(0=$ very untrue about me to $4=$ very true about me). Participants also rated how disgusting they found four scenarios (e.g. "You are about to drink a glass of milk when you smell that it is spoiled") on a scale from $0=$ not disgusting at all to $4=$ extremely disgusting. When combined as a single 8 -item scale, internal consistency was acceptable $(\alpha=.69)$.

Willingness to eat was measured by asking participants to express how willing they were to engage with cultured meat on a scale of $1=$ No, definitely not, to $5=$ Yes, definitely. 
The specific questions were "Would you be willing to try cultured meat?" and "Would you be willing to eat cultured meat regularly". These items were highly correlated. $r(325)=.84, p<$ .001. As such, we took the mean of the two measures to explore participants' general willingness to eat cultured meat. ${ }^{1}$

Perceptions of benefits were measured by asking participants to express how "healthy", "natural”, "environmentally friendly", "ethical”, “appealing”, and "tasty" they thought cultured meat was relative to farmed meat $(1=$ much less to $5=$ much more $)$. The mean of the six items formed a reliable scale $(\alpha=.87)$ with higher scores representing more positive perceptions.

Absolute opposition was measured using two items adapted from Scott et al. (2016). Participants responded "agree" or "disagree" to two questions: "This should be prohibited no matter how great the risks and benefits are from allowing it" and "It is equally wrong to allow some of this to happen as to allow twice as much to happen. The amount doesn't matter"2. These two items were analyzed separately, with "disagree" responses coded as 0 and "agree" responses coded as 1 .

\section{Results}

\section{Descriptive Statistics}

All analyses were conducted in SPSS version 25. Participants scored above the midpoint on naturalness bias and just above the midpoint on distrust in science. Participants scored below the midpoint on speciesism, SDO, food neophobia, food and hygiene disgust

\footnotetext{
${ }^{1}$ Participants also answered the question "How much would you be willing to pay for cultured meat relative to farmed meat" on a scale of $1=$ much less to $5=$ much more. We excluded this from analyses as it was not a pure measure of attitude and was potentially confounded by other psychological mechanisms associated with cost.

2 Participants also answered two other absolute opposition questions "This would be wrong even if everyone thought it was right" and "I do not oppose this". In the interest of transparency, we ran the same analyses on these two variables and yielded identical results to those reported below - food neophobia, food and hygiene disgust, and conspiratorial ideation were all significant predictors ( $p$ s $<.015)$. The only difference between these findings and those for the reported variables is that age, sex, education and political conservatism contributed to agreement with the statement "I do not oppose this" where males, more educated people, younger people and those who were politically liberal were more likely to agree than females, older people, less educated people, and those who are politically conservative.
} 
sensitivity, and conspiratorial ideation. Participants were also slightly below the midpoint for willingness to eat cultured meat and perceptions of benefits. However, for the two dichotomous measures of absolute opposition, the average participant leaned towards rejecting rather than agreeing with the statements (see Table 2).

Table 2.

Means and standard deviations for outcome measures and psychological predictors.

\begin{tabular}{llcc}
\hline Measure & Mean & SD & Scale Endpoints \\
\hline Willingness to eat cultured meat & 2.91 & 1.24 & $1-5$ \\
Perceptions of benefits & 2.77 & 0.86 & $1-5$ \\
Prohibited no matter what & 0.32 & 0.47 & $0-1$ \\
Equally wrong no matter how much & 0.42 & 0.49 & $0-1$ \\
Political conservatism & 5.16 & 2.44 & $1-9$ \\
Naturalness bias & 4.84 & 1.15 & $1-7$ \\
Speciesism & 3.35 & 1.35 & $1-7$ \\
SDO & 3.13 & 1.07 & $1-7$ \\
Distrust in science & 4.26 & 1.26 & $1-7$ \\
Conspiratorial ideation & 2.67 & 1.07 & $1-5$ \\
Food neophobia & 3.55 & 1.13 & $1-7$ \\
F\&H disgust sensitivity & 3.05 & 0.70 & \\
\hline
\end{tabular}

Note. "Prohibited no matter what" and "Equally wrong no matter how much" were coded as 0 $=$ disagree, $1=$ agree. $\mathrm{F} \& \mathrm{H}$ refers to food and hygiene subscales of the disgust sensitivity scale.

\section{Correlations among predictors}

We employed Pearson's correlations to explore the relationships among predictor variables (Table 3). Moderate correlations were found among the predictors, but there was no evidence of multicollinearity. 


\section{Regression Analyses}

Willingness to eat cultured meat. We conducted a hierarchical linear regression to identify the demographic (Step 1) and psychological (Step 2) predictors of people's willingness to eat cultured meat (Table 4). The decision to undertake stepwise processing (here, and in all subsequent regression analyses) was to allow us to identify the unique role of the psychological mechanisms, while controlling for demographic predictors that have previously been established as predictors of attitudes toward cultured meat.

Predictors entered at Step 1 explained a significant amount of variance in willingness to eat cultured meat, $R^{2}=.04, p<.001$. Consistent with previous research (Wilks \& Phillips, 2017), younger people, males, those with higher incomes, and those who did not restrict their meat-eating were all more willing to eat cultured meat. Inclusion of the psychological predictors at Step 2 explained a significant amount of extra variance over and above the demographics, $R^{2}=.12, R_{\mathrm{ch}}^{2}=.09, p<.001$. Age and gender remained significant predictors, while education and eating habits were no longer predictive Political conservatism and food neophobia were the only significant unique predictors, such that those who are less politically conservative and those with lower levels of food neophobia were more willing to eat cultured meat. 
Table 3. Correlations among predictors.

\begin{tabular}{|c|c|c|c|c|c|c|c|c|c|c|c|}
\hline & 2 & 3 & 4 & 5 & 6 & 7 & 8 & 9 & 10 & 11 & 12 \\
\hline 1. Political conservatism & $-.09^{* * *}$ & $.26^{* * *}$ & $.35^{* * *}$ & $.14^{* * * *}$ & -.03 & $.12^{* * * *}$ & .03 & $.13^{* * *}$ & $-.17^{* * *}$ & $.08^{* * * *}$ & $.06^{*}$ \\
\hline 2. Naturalness bias & & $-.25^{* * *}$ & $-.25^{* * *}$ & $.24^{* * *}$ & $.22^{* * *}$ & $-.09^{* * * *}$ & $.22^{* * *}$ & .03 & .00 & .01 & .05 \\
\hline 3. Speciesism & & & $.40^{* * * *}$ & .04 & .01 & .05 & $-.07^{*}$ & -.02 & -.04 & .03 & .03 \\
\hline 4. SDO & & & & $.12^{* * *}$ & $.12^{* * *}$ & $.14^{* * * *}$ & .01 & .05 & -.03 & $.09^{* * *}$ & $.08^{* * *}$ \\
\hline 5. Distrust in science & & & & & $.45^{* * * *}$ & $.09^{* * *}$ & $.23^{* * *}$ & $.07^{*}$ & $-.11^{* * *}$ & $.14^{* * *}$ & $.16^{* * *}$ \\
\hline 6. Conspiratorial ideation & & & & & & $.10^{* * *}$ & $.25^{* * *}$ & $.07^{*}$ & -.02 & $.22^{* * *}$ & $.18^{* * *}$ \\
\hline 7. Food neophobia & & & & & & & $.15^{* * *}$ & $.28^{* * *}$ & $-.13^{* * *}$ & $.19^{* * *}$ & .16 \\
\hline 8. $\mathrm{F} \& \mathrm{H}$ disgust sensitivity & & & & & & & & $.10^{* * *}$ & -.03 & $.22^{* * *}$ & $.16^{* * *}$ \\
\hline 9. Willingness to eat & & & & & & & & & $-.72^{* * *}$ & $.47^{* * *}$ & $.41^{* * *}$ \\
\hline 10. Perceptions of benefits & & & & & & & & & & $-.39^{* * *}$ & $-.36^{* * *}$ \\
\hline 11. Prohibit no matter what & & & & & & & & & & & $.61^{* * *}$ \\
\hline 12. Equally wrong & & & & & & & & & & & \\
\hline
\end{tabular}


4 Demographic and psychological predictors of willingness to eat cultured meat.

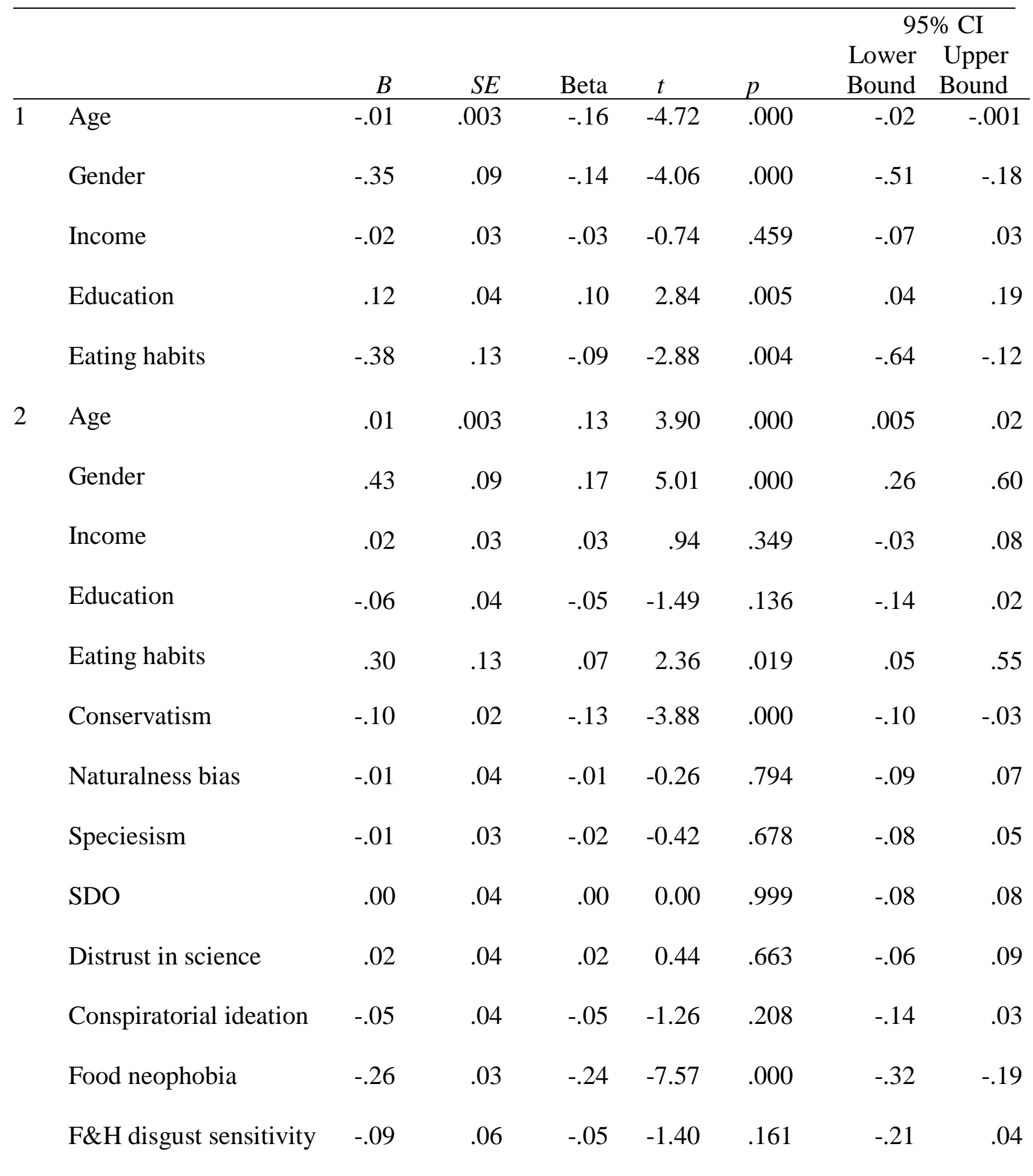

5 Note. Gender was coded as $0=$ male, $1=$ female; meat consumption was coded as eating all 6 meat $=0$; meat restricting $=1$. F\&H refers to food and hygiene subscales of the disgust 7 sensitivity scale. Reported values correspond to the regression step denoted in the left-hand 8 column. 
10 Perceptions of benefits. We then examined the demographic (Step 1) and psychological (Step

11 2) predictors of people's tendency to perceive benefits of cultured meat relative to farmed meat

12 (Table 5). The demographics entered at Step 1 explained a significant amount of variance, $R^{2}=$

$13.02, p<.001$. Specifically, younger people, males, and those with higher levels of education

14 were more likely to perceive benefits of cultured meat. Inclusion of the psychological

15 predictors at Step 2 explained a significant amount of extra variance over and above the

16 demographics, $R^{2}=.07, R_{\mathrm{ch}}^{2}=.05, p<.001$. Age and gender remained significant predictors,

17 while education was no longer predictive. Political conservatism, distrust in science, and food

18 neophobia were all significantly associated with negative perceptions of cultured meat relative

19 to farmed meat.

20 Table 5.

21 Demographic and psychological predictors of perceived benefits of cultured meat.

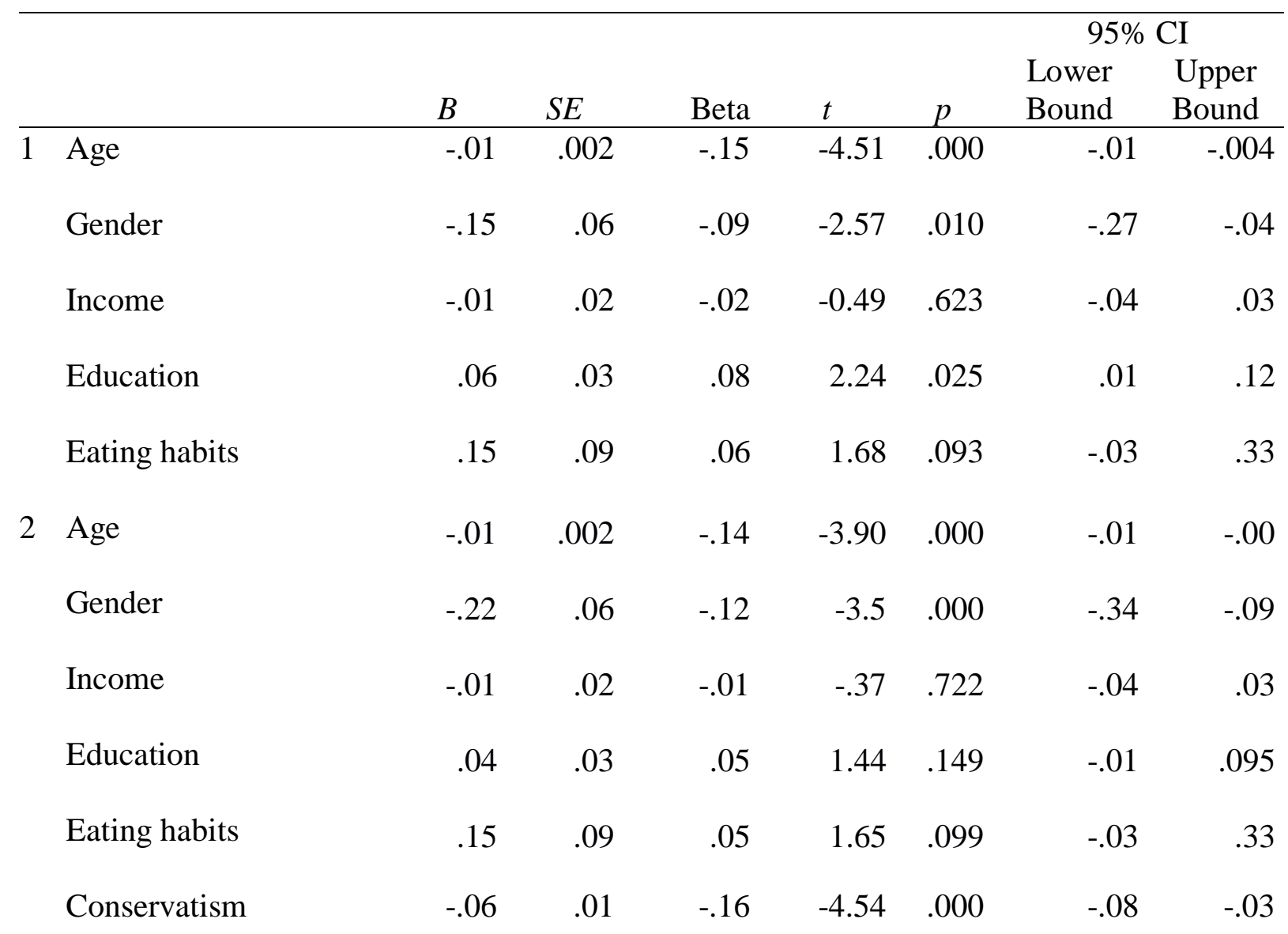




$\begin{array}{lccccccr}\text { Naturalness bias } & .02 & .03 & .03 & 0.79 & .432 & -.03 & .08 \\ \text { Speciesism } & -.04 & .02 & -.05 & -1.46 & .145 & -.08 & .01 \\ \text { SDO } & .03 & .03 & .04 & 1.02 & .308 & -.03 & .09 \\ \text { Distrust in science } & -.05 & .03 & -.07 & -1.99 & .047 & -.10 & -.001 \\ \text { Conspiratorial ideation } & -.01 & .03 & -.01 & -0.15 & .878 & -.06 & .06 \\ \text { Food neophobia } & -.07 & .02 & -.09 & -2.70 & .007 & -.11 & -.02 \\ \text { F\&H disgust sensitivity } & -.03 & .05 & -.03 & -0.73 & .468 & -.12 & .06\end{array}$

Note. Gender was coded as $0=$ male, $1=$ female; meat consumption was coded as eating all meat $=0$; meat restricting $=1 . F \& H$ refers to food and hygiene subscales of the disgust sensitivity scale. Reported values correspond to the regression step denoted in the left-hand column.

Absolute opposition. We conducted hierarchical binomial regressions to identify demographic (Step 1) and psychological (Step 2) predictors of each of two measures of absolute opposition to cultured meat. For the first analysis, the absolute opposition variable was agreement with the statement "This should be prohibited no matter how great the benefits and minor the risks are from allowing it" (see Table 6). The basic model correctly classified $68.2 \%$ of cases, while the final model correctly classified $72.2 \%$ of cases. The final model explained $12.0 \%$ (Cox and Snell) to $16.8 \%$ (Nagelkerke) of the variance in absolute opposition to cultured meat. At Step 1, no demographic factors were significant predictors. At Step 2, age, gender, conspiratorial ideation, food neophobia, and food and hygiene disgust sensitivity were found to be significant predictors. Specifically, older people, females, those higher in conspiratorial ideation, food neophobia, and food and hygiene disgust sensitivity were all more likely to agree with the statement.

For the second analysis, the absolute opposition variable was agreement with the statement "It is equally wrong to allow some of this to happen as it is to allow twice as much to happen. The amount doesn't matter" (see Table 7). The basic model correctly classified 58.4\% 
42 of cases, while final model correctly classified $64.8 \%$ of cases. The final model explained

$438.9 \%$ (Cox and Snell) to $12.0 \%$ (Nagelkerke) of the variance in absolute opposition to cultured

44 meat. At Step 1, females were significantly more likely to agree with the statement than males.

45 At Step 2, females, older people, those higher in conspiratorial ideation, food neophobia, and

46 food and hygiene disgust sensitivity were again more likely to agree with the statement.

47

48 
49

50

51

52

53

Table 6.

Demographic and psychological predictors of agreement with the statement "This should be prohibited no matter how great the benefits and minor the risks are from allowing it"

\section{$95 \% \mathrm{CI}$}

\begin{tabular}{rllllllllr} 
& & \multicolumn{1}{c}{$B$} & SE & Wald & $d f$ & $p$ & $\operatorname{Exp}(\mathrm{B})$ & Lower & Upper \\
\hline 1 & Age & .004 & .01 & 0.97 & 1 & .324 & 1.00 & .996 & 1.01
\end{tabular}

Gender .22 .15

2.22

1.137

Income

$-.08$

.05

3.01

$1 \quad .083$

.92

.84

1.01

Education

$-.13 \quad .07$

3.32

.88

.76

1.01

Eating habits

Gender

.34

.17

4.04

$1 \quad .044$

$1.41 \quad 1.01$

1.96

Income

$-.08 \quad .05$

2.29

$1 \quad .130$

$.93 \quad .84$

Education

$-.06 \quad .08$

.50

$1 \quad .480$

$.95 \quad .81$

Eating habits

$.19 \quad .24$

.61

1.433

Conservatism

$.07 \quad .03$

$\begin{array}{lll}3.67 \quad 1 & .055\end{array}$

$1.07 \quad .999$

Naturalness bias

$-.05 \quad .08$

$\begin{array}{lll}0.33 & 1 & .569\end{array}$

$.96 \quad .82$

Speciesism

$.04 \quad .07$

$\begin{array}{lll}0.34 \quad 1 & .561\end{array}$

$1.04 \quad .91$

SDO

$.10 \quad .08$

$\begin{array}{lll}1.53 & 1 & .215\end{array}$

$1.11 \quad .94$

Distrust in science

.004

.07

$\begin{array}{lll}0.00 \quad 1 & .954\end{array}$

1.00

.87

Conspiratorial ideation

.36

.09

17.75

1.000

$1.43 \quad 1.21$

1.69

Food neophobia

.22

.07

10.74

$1 \quad .001$

$1.25 \quad 1.09$

F\&H disgust sensitivity

.69

$.13 \quad 29.35$

$1 \quad .000$

$2.00 \quad 1.56$ column. 
59 Table 7.

60 Demographic and psychological predictors of agreement with the statement "It is equally

61 wrong to allow some of this to happen as it is to allow twice as much to happen"

\begin{tabular}{|c|c|c|c|c|c|c|c|c|c|}
\hline & \multirow[b]{2}{*}{$B$} & \multirow[b]{2}{*}{$S E$} & \multirow[b]{2}{*}{ Wald } & \multirow[b]{2}{*}{$d f$} & \multirow[b]{2}{*}{$p$} & \multirow[b]{2}{*}{$\operatorname{Exp}(B)$} & \multicolumn{2}{|c|}{$95 \% \mathrm{CI}$} \\
\hline & & & & & & & & Lower & Upper \\
\hline & Age & .01 & .004 & 1.62 & 1 & .203 & 1.005 & .997 & 1.01 \\
\hline & Gender & .30 & .14 & 4.61 & 1 & .032 & 1.36 & 1.03 & 1.79 \\
\hline & Income & -.05 & .05 & 1.06 & 1 & .303 & .96 & .87 & 1.04 \\
\hline & Education & -.06 & .07 & 0.65 & 1 & .419 & .95 & .83 & 1.08 \\
\hline & Eating habits & .17 & .22 & 0.61 & 1 & .436 & 1.18 & .77 & 1.81 \\
\hline \multirow[t]{13}{*}{2} & Age & .01 & .01 & 6.39 & 1 & .011 & 1.01 & 1.00 & 1.02 \\
\hline & Gender & .45 & .16 & 8.23 & 1 & .004 & 1.57 & 1.15 & 2.14 \\
\hline & Income & -.04 & .05 & .54 & 1 & .463 & .97 & .88 & 1.06 \\
\hline & Education & .01 & .07 & .03 & 1 & .867 & 1.01 & .88 & 1.17 \\
\hline & Eating habits & .02 & .23 & .01 & 1 & .937 & 1.02 & .65 & 1.61 \\
\hline & Conservatism & .02 & .03 & 0.22 & 1 & 640 & 1.02 & .95 & 1.08 \\
\hline & Naturalness bias & -.11 & .07 & 2.41 & 1 & .121 & .89 & .77 & 1.03 \\
\hline & Speciesism & .07 & .06 & 1.45 & 1 & .228 & 1.08 & .96 & 1.22 \\
\hline & SDO & .07 & .08 & 0.86 & 1 & .354 & 1.07 & .93 & 1.24 \\
\hline & Distrust in science & .13 & .07 & 3.58 & 1 & .059 & 1.13 & .995 & 1.29 \\
\hline & Conspiratorial ideation & .24 & .08 & 9.38 & 1 & .002 & 1.27 & 1.09 & 1.48 \\
\hline & Food neophobia & .21 & .06 & 11.17 & 1 & .001 & 1.23 & 1.09 & 1.39 \\
\hline & $\mathrm{F} \& \mathrm{H}$ disgust sensitivity & .47 & .12 & 15.91 & 1 & .000 & 1.60 & 1.27 & 2.01 \\
\hline
\end{tabular}

62 Note. Gender was coded as $0=$ male, $1=$ female; meat consumption was coded as eating all 63 meat $=0$; meat restricting $=1$. F\&H refers to food and hygiene subscales of the disgust 64 sensitivity scale. Reported values correspond to the regression step denoted in the left-hand 65 column. 


\section{Discussion}

The aim of the current study was to identify the psychological roots of people's attitudes towards - and intentions to eat - cultured meat. Drawing on the notion of attitude roots (Hornsey \& Fielding, 2017), we explored three broad factors that could potentially be implicated in opposition to cultured meat: worldviews, conspiratorial ideation, and fears/phobias.

The strongest and most consistent predictor of people's willingness to eat cultured meat - and their perceptions of the benefits of cultured meat - was food neophobia. Specifically, the more participants had a general aversion to new taste and food experiences, the less willing they were to eat cultured meat and the less they acknowledged benefits of cultured meat. The next most robust relationship was the tendency for political conservatives to be more negative in their attitudes toward cultured meat. It should be noted that this relationship emerges over and above certain constructs that are typically associated with conservatism, such as speciesism and SDO. This effect is somewhat curious given that cultured meat has not (at least to our knowledge) been embroiled in the sort of "culture wars" that have previously polarized attitudes toward stem cell research and climate change. We speculate that belief in the free market may be one construct that would contribute and was not captured here: conservatives may have been more hesitant toward cultured meat because of the fact that it poses a potential threat to the existing meat industry (see Lewandowsky, Gignac, \& Oberauer, 2013, for a discussion of the role of free-market beliefs in opposition to other scientific discoveries). An alternative possibility is that conservative participants may embrace traditional food systems and eating habits. Clarifying the reasons why conservatives are hesitant about cultured meat remains a challenge for future research. Interestingly, distrust in food science had only a modest relationship with perceptions of the benefits of cultured meat, and no relationship at all 
with willingness to eat it. This may be a product of the question framing; perhaps food scientists are not the target of public distrust in comparison to scientists generally.

Two of our criterion variables measured "absolute" opposition to cultured meat: "This should be prohibited no matter how great the benefits and minor the risks are from allowing it" and "It is equally wrong to allow some of this to happen as to allow twice as much to happen.

The amount doesn't matter". Scott and colleagues (2016) argue that absolute opposition emerges in response to "protected" or "sacred values". They are regarded as axiomatic, requiring no further justification, and are protected from trade-offs with secular values.

Previous research suggests that positive and negative information about cultured meat changes people's attitude in the direction of the information (Bekker, Fischer, Tobi, \& van Trijp, 2017; Verbeke, Sans, \& Loo, 2015). However, our data suggest there may be limits to the utility of changing attitudes merely through information and education. Specifically, around one third of participants in our sample (30.3\% and 39.8\% depending on the question) indicated "absolute" opposition to cultured meat, suggesting that their attitudes are insensitive to arguments about costs and benefits. For this subset of the population, it seems reasonable to suggest that providing further information and education about the benefits of cultured meat will not necessarily improve attitudes.

Interestingly, when the absolute opposition items were used as outcome variables, the pattern of prediction was somewhat different. Again, food neophobia predicted opposition to cultured meat on both measures, but this time food and hygiene disgust sensitivity subscales was also a significant predictor. Neophobia might motivate such absolute opposition where fear prevents rational evaluation of outcomes and people perceive cultured meat negatively regardless of the risks and benefits. This aligns with research noted earlier where Siegrist and Sütterlin (2017) find that a health risk from cultured meat is much less acceptable than the same risk from farmed meat. In terms of disgust, these findings suggest that non-negotiable 
117 resistance to cultured meat is more prevalent in those who are disgust sensitive in domains of

118 hygiene and food. Notably, our interpretation is limited to the two subscales measured - food

119 and hygiene. It is possible that the relationship between disgust sensitivity as reflected by the

120 current subscales and cultured meat attitudes would also be present for other measures of

121 disgust sensitivity. In future research, disgust sensitivity should be measured more broadly (the

122 full disgust sensitivity scale) to explore whether this relationship persists.

123 Interestingly, political conservatism was not a reliable predictor of absolute opposition,

124 despite being a highly significant predictor of attitudes and intentions. However, conspiratorial

125 ideation did predict absolute opposition: the more people were prone to believe in conspiracies,

126 the more likely they were to feel absolutely opposed to cultured meat. This relationship adds to

127 an emerging body of research suggesting that people's general willingness to believe

128 conspiracy theories is implicated in a tendency to resist scientific messages, for example

129 around climate change, vaccination, genetically modified food, and the link between HIV and

130 AIDS (see Hornsey et al., 2018a, 2018b, Lewandowsky et al., 2013, Lewandowsky et al.,

131 2015). People who are prone to believing conspiracies work from the assumption that there are

132 powerful small groups who exert influence in covert ways over large portions of the public for

133 their own benefit (Douglas \& Sutton, 2018). Given this, it seems plausible that conspiracy

134 theorists are more likely to believe that the people creating cultured meat (scientists, large

135 corporations) are doing so for sinister or self-serving purposes, and with the end goal of

136 controlling or benefiting from public consumption. However, this is speculative: although

137 some have documented the various ways in which conspiracy theorists have challenged

138 science and individual scientists (Goertzel, 2010), we are aware of no research that has yet

139 identified the specific conspiracy theories that might promote skepticism around cultured meat.

140 Given the findings documented here, we suggest that this should be a priority for future

141 research. 
Importantly, there were also several mechanisms that did not predict perceptions of

143 cultured meat. For example, SDO and speciesism were not predictive of any outcome

144 measures. The null result on speciesism, in particular, suggests that concerns about animal

145 ethics may not (yet) be a central factor in determining attitudes toward cultured meat.

146 Possibly the most striking null result was the failure to find a relationship between

147 naturalness bias and our outcome measures. Research has repeatedly identified concerns

148 around naturalness as a key factor predicting negative attitudes to cultured meat: this is a

149 common theme in qualitative studies, and is a consistent predictor of negativity toward

150 cultured meat in quantitative studies (Siegrist \& Sütterlin, 2017; Siegrist et al., 2018). In

151 contrast, in the current study, it was the least significant predictor (even at the bivariate level,

152 controlling for nothing else, naturalness bias shared no significant relationship with any of the

153 outcome variables, all $r \mathrm{~s}<.05, p s>.10)$. In accounting for this difference, it is helpful to

154 reflect on the different methods of examining naturalness as a mechanism. In qualitative

155 research - as well as the quantitative research by Siegrist and colleagues (2018) - participants

156 were asked explicitly about how natural they perceived cultured meat to be. In contrast, in the

157 current study, we asked participants about their general naturalness bias, and subsequently

158 asked about cultured meat attitudes; thus, there was no reference to cultured meat when

159 discussing natural concerns.

160 Another possible reason for the discrepant findings is that our scale is not adequately

161 capturing the construct. We acknowledge that this is a scale devised by us, and has not yet

162 been subjected to psychometric validation. Having said that, the internal reliability of the scale

163 was high. Furthermore, the items possess face validity. If naturalness concerns are a major

164 factor in driving opposition to cultured meat, then on face value we would expect items such as

165 "natural food is safer than processed food" and "things that are natural are inherently better

166 than things that are not natural" should correlate with our outcome measures. 
An alternative possibility is that people are using the term "unnatural" to attach

168 language and logic to something that is affectively motivated. In his model of moral

169 intuitionism, Haidt (2001) argued that the typical assumption that reasoning precedes

170 judgements is often incorrect. Rather, people often reach judgements - experienced as

171 intuitions that lie outside conscious reasoning - and then engage in a posthoc process of

172 reasoning to justify those intuitions. One such response that Haidt spoke about is disgust;

173 people experience disgust at an act, and then engage in a posthoc process of explaining their

174 disgust through reason. It is possible that this is what is happening with attitudes to cultured

175 meat: when people use terms like 'unnatural', they are seeking a way to justify feelings of

176 wrongness or disgust. Obviously, it is difficult to provide smoking-gun evidence for such a

177 process, and so this interpretation remains speculative. If true, however, it might suggest that

178 interventions addressing naturalness bias may not be successful in improving attitudes to

179 cultured meat.

180 Although the current study provides some interesting insights about the psychological

181 underpinnings of responses to cultured meat, the cross-sectional correlational nature of the data

182 means that we cannot comment on causal relationships between variables. It was also clear that

183 the variables included in our regression models explained a modest amount of the variance in

184 participants' responses to cultured meat, indicating that there is room for future research to

185 explore other predictors of this emerging food technology. For example, we did not directly

186 test the role of concern for animal welfare in our model, though we employ a number of scales

187 that relate to such attitudes. Similarly, some of these attitudes may be accounted for by general

188 attitudes toward meat consumption, which also was not measured here. Finally, it may be that

189 stronger associations between the predictor variables and responses to cultured meat would

190 emerge for situations in which responses moved from the hypothetical to the actual. 
191 Overall, these results indicate that the attitudes to cultured meat are underpinned by a number

192 of psychological roots. In terms of attitude and intentions, the most powerful predictors (in

193 order of strength) were food neophobia and political conservatism. Distrust in food science

194 was a less significant predictor of attitudes, and not significant for intentions to engage. When

195 it comes to absolute opposition to cultured meat, the strongest predictors were food and

196 hygiene disgust sensitivity, food neophobia, and conspiratorial ideation. Many current

197 approaches to cultured meat research employ the knowledge-deficit approach (e.g. in Bekker,

198 Fischer, Tobi, \& van Trijp, 2017; Verbeke, Sans, \& Van Loo, 2015) - the assumption that

199 further education about the benefits of cultured meat is sufficient to induce attitude change.

200 Although there are clear benefits to this approach, the current data suggest that information

201 alone may not be sufficient. It appears that many psychological mechanisms underpin our

202 perceptions of cultured meat - we are motivated reasoners; thus, mere additional information is

203 likely to be unsuccessful at changing our minds. Instead, there could be value in identifying

204 new frames to educate individuals about cultured meat in ways that address the underlying

205 worldviews, fears, and conspiratorial mindsets that are associated with people's resistance.

206 One option might include approaches aimed at highlighting changing social norms around

207 acceptance of cultured meat; if it can be communicated that sizable portions of the population

208 are comfortable with cultured meat (as our data suggest they are) then this might help it appear

209 less threatening, disgusting or suspicious. Another option might include focusing on the 'clean

210 meat' interpretation of cultured meat. By highlighting the lowered risk of disease exposure in

211 cultured meat relative to farmed meat practices, those who are high in disgust sensitivity may

212 be more inclined towards cultured meat. Conspiratorial ideation appears the most difficult to

213 address. However, highlighting the (potential) vested interests of those in the farmed meat

214 industry might even the playing field between cultured and farmed meat, allowing the focus to 
215 shift to other benefits associated with cultured meat. We note that these are speculative,

216 specific approaches remain a question for further exploration.

217

218 


\section{References}

221

222

223

224

225

226

227

228

229

230

231

232

233

234

235

Ammann, J., Hartmann, C., \& Siegrist, M. (2017). Does food disgust sensitivity influence eating behaviour? Experimental validation of the Food Disgust Scale. Food Quality and Preference. https://doi.org/https://doi.org/10.1016/j.foodqual.2017.12.013

Bekker, G. A., Fischer, A. R. H., Tobi, H., \& van Trijp, H. C. M. (2017). Explicit and implicit attitude toward an emerging food technology: The case of cultured meat. Appetite, 108, 245-254. https://doi.org/10.1016/j.appet.2016.10.002

United States Census Bureau. (2016). QuickFacts. Retrieved from https://www.census.gov/quickfacts/fact/table/US/PST045217

Caviola, L., Everett, J. A. C., \& Faber, N. S. (2018). The moral standing of animals: Towards a psychology of speciesism. Journal of Personality and Social Psychology.

Critchley, C. R. (2008). Public opinion and trust in scientists: the role of the research context, and the perceived motivation of stem cell researchers. Public Understanding of Science, 17(3), 309-327. https://doi.org/10.1177/0963662506070162

Demattè, M. L., Endrizzi, I., \& Gasperi, F. (2014). Food neophobia and its relation with olfaction. Frontiers in Psychology, 5, 127. https://doi.org/10.3389/fpsyg.2014.00127

Dhont, K., \& Hodson, G. (2014). Why do right-wing adherents engage in more animal exploitation and meat consumption? Personality and Individual Differences, 64, 12-17. https://doi.org/https://doi.org/10.1016/j.paid.2014.02.002

Dhont, K., Hodson, G., Costello, K., \& MacInnis, C. C. (2014). Social dominance orientation connects prejudicial human-human and human-animal relations. Personality and Individual Differences, 61-62, 105-108. https://doi.org/https://doi.org/10.1016/j.paid.2013.12.020

Douglas, K. M., \& Sutton, R. M. (2018). Why conspiracy theories matter: A social 
psychological analysis. European Review of Social Psychology, 29, 256-298.

Douglas, M., \& Wildavsky, A. B. (1982). Risk and Culture: An essay on the selection of technical and environmental dangers. Berkeley: University of California Press.

Fessler, D. M. T., Arguello, A. P., Mekdara, J. M., \& Macias, R. (2003). Disgust sensitivity and meat consumption: a test of an emotivist account of moral vegetarianism. Appetite, 41(1), 31-41. https://doi.org/10.1016/S0195-6663(03)00037-0

Gaskell, G. (1999). Worlds apart? The reception of genetically modified foods in Europe and the U.S. Science., 285(5426), 384-387.

Goertzel, T. (2010). Conspiracy theories in science. EMBO Reports, 11, 493-499.

Haidt, J. (2001). The Emotional Dog and Its Rational Tail: A Social Intuitionist Approach to Moral Judgment. Psychological Review, 108(4), 814. https://doi.org/10.1037/0033295X.108.4.814

Haidt, J., McCauley, C., \& Rozin, P. (1994). Individual differences in sensitivity to disgust: A scale sampling seven domains of disgust elicitors. Personality and Individual Differences, 16(5), 701-713. https://doi.org/https://doi.org/10.1016/0191-8869(94)90212-7

Hocquette, A., Lambert, C., Sinquin, C., Peterolff, L., Wagner, Z., Bonny, S. P. F., ... Hocquette, J.-F. (2015). Educated consumers don't believe artificial meat is the solution to the problems with the meat industry. Journal of Integrative Agriculture, 14(2), 273284. https://doi.org/http://dx.doi.org/10.1016/S2095-3119(14)60886-8

Hoek, A. C., Luning, P. A., Weijzen, P., Engels, W., Kok, F. J., \& de Graaf, C. (2011). Replacement of meat by meat substitutes. A survey on person- and product-related factors in consumer acceptance. Appetite, 56(3), 662-673. https://doi.org/https://doi.org/10.1016/j.appet.2011.02.001

Hornsey, M. J., \& Fielding, K. (2017). Attitude roots and Jiu Jitsu persuasion: Understanding and overcoming the motivated rejection of science. American Psychologist, 72(5), 459- 
473.

270

Hornsey, M. J., Harris, E. A., \& Fielding, K. S. (2018a). Relationships among conspiratorial beliefs, conservatism and climate scepticism across nations. Nature Climate Change, 8 , 614-620.

Hornsey, M. J., Harris, E. A., \& Fielding, K. S. (2018b). The psychological roots of antivaccination attitudes: A 24-nation investigation. Health Psychology, 37, 307-315. https://doi.org/10.1037/hea0000586

Hornsey, M. J., Harris, E., Bain, P., \& Fielding, K. (2016). Meta-analyses of the determinants and outcomes of belief in climate change. Nature Climate Change, 6(6), 622-626. https://doi.org/10.1038/nclimate2943

Gallup Incorporated. (2012). In U.S., 5\% Consider Themselves Vegetarians. Retrieved from http://news.gallup.com/poll/156215/consider-themselves-vegetarians.aspx

Gallup Incorporated. (2017). U.S. Conservatives Outnumber Liberals by Narrowing Margin. Retrieved from http://news.gallup.com/poll/201152/conservative-liberal-gap-continuesnarrow-tuesday.aspx

Kahan, D. M., Braman, D., Cohen, G. L., Gastil, J., \& Slovic, P. (2010). Who Fears the HPV Vaccine, Who Doesn't, and Why? An Experimental Study of the Mechanisms of Cultural Cognition. Law and Human Behavior, 34(6), 501-516. https://doi.org/10.1007/s10979009-9201-0

Laestadius, L. I., \& Caldwell, M. A. (2015). Is the future of meat palatable? Perceptions of in vitro meat as evidenced by online news comments. Public Health Nutrition, 18(13), 2457-2467. https://doi.org/10.1017/S1368980015000622

Lewandowsky, S., Gignac, G. E., \& Oberauer, K. (2013). The Role of Conspiracist Ideation and Worldviews in Predicting Rejection of Science. PLOS ONE, 8(10), 1-11. https://doi.org/10.1371/journal.pone.0075637 
294 Lewandowsky, S., Gignac, G. E., \& Oberauer, K. (2015). The Robust Relationship Between

295 Conspiracism and Denial of (Climate) Science. Psychological Science, 26(5), 667-670.

296 https://doi.org/10.1177/0956797614568432

297 Lewandowsky, S., Oberauer, K., \& Gignac, G. E. (2013). NASA Faked the Moon Landing-

298 Therefore, (Climate) Science Is a Hoax: An Anatomy of the Motivated Rejection of

299 Science. Psychological Science, 24(5), 622-633.

$300 \quad$ https://doi.org/10.1177/0956797612457686

301 Marcu, A., Gaspar, R., Rutsaert, P., Seibt, B., Fletcher, D., Verbeke, W., \& Barnett, J. (2015).

302 Analogies, metaphors, and wondering about the future: Lay sense-making around

303 synthetic meat. Public Understanding of Science, 24(5), 547-562.

$304 \quad$ https://doi.org/10.1177/0963662514521106

305 Martin, M. J., Thottathil, S. E., \& Newman, T. B. (2015). Antibiotics Overuse in Animal

306 Agriculture: A Call to Action for Health Care Providers. American Journal of Public

$307 \quad$ Health, 105(12), 2409. https://doi.org/10.2105/AJPH.2015.302870

308 Milfont, T. L., Richter, I., Sibley, C. G., Wilson, M. S., \& Fischer, R. (2013). Environmental

309 Consequences of the Desire to Dominate and Be Superior. Personality and Social

$310 \quad$ Psychology Bulletin, 39(9), 1127-1138. https://doi.org/10.1177/0146167213490805

311 Food and Agriculture Data of the United Nations. (n.d.). Food and Agriculture Data. Retrieved

312 from http://www.fao.org/faostat/en/\#home

313 Olatunji, B. O., Williams, N. L., Tolin, D. F., Abramowitz, J. S., Sawchuk, C. N., Lohr, J. M.,

314 \& Elwood, L. S. (2007). The Disgust Scale: item analysis, factor structure, and

315 suggestions for refinement. Psychological Assessment, 19(3), 281-297.

316 https://doi.org/10.1037/1040-3590.19.3.281

317 Petrovic, Z., Djordjevic, V., Milicevic, D., Nastasijevic, I., \& Parunovic, N. (2015). Meat

318 Production and Consumption: Environmental Consequences. Procedia Food Science, 5 , 
235-238. https://doi.org/http://dx.doi.org/10.1016/j.profoo.2015.09.041

Piazza, J., Ruby, M. B., Loughnan, S., Luong, M., Kulik, J., Watkins, H. M., \& Seigerman, M. (2015). Rationalizing meat consumption. The 4Ns. Appetite, 91, 114-128. https://doi.org/https://doi.org/10.1016/j.appet.2015.04.011

Pliner, P., \& Hobden, K. (1992). Development of a scale to measure the trait of food neophobia in humans. Appetite, 19(2), 105-120. https://doi.org/10.1016/01956663(92)90014-W

Post, M. J. (2014a). An alternative animal protein source: Cultured beef. . Annals of the New York Academy of Sciences, 1328(1), 29-33. https://doi.org/10.1111/nyas.12569

Post, M. J. (2014b). Cultured beef: medical technology to produce food. Journal of the Science of Food and Agriculture, 94(6), 1039-1041. https://doi.org/10.1002/jsfa.6474

Pratto, F., Sidanius, J., Stallworth, L. M., \& Malle, B. F. (1994). Social Dominance Orientation: A Personality Variable Predicting Social and Political Attitudes. Journal of Personality and Social Psychology, 67(4), 741-763. https://doi.org/10.1037/00223514.67.4.741

Rabinowitz, M., Latella, L., Stern, C., \& Jost, J. T. (2016). Beliefs about Childhood Vaccination in the United States: Political Ideology, False Consensus, and the Illusion of Uniqueness. PLOS ONE, 11(7), 1-19. https://doi.org/10.1371/journal.pone.0158382

Raudenbush, B., Schroth, F., Reilley, S., \& Frank, R. A. (1998). Food Neophobia, Odor Evaluation and Exploratory Sniffing Behavior. Appetite, 31(2), 171-183. https://doi.org/10.1006/appe.1998.0161

Scott, S. E., Inbar, Y., \& Rozin, P. (2016). Evidence for Absolute Moral Opposition to Genetically Modified Food in the United States. Perspectives on Psychological Science, 11(3), 315-324. https://doi.org/10.1177/1745691615621275

Scott, S. E., \& Rozin, P. (2017). Are additives unnatural? Generality and mechanisms of 

additivity dominance. Judgment and Decision Making, 12(6), 572-583.

Siegrist, M., \& Sütterlin, B. (2017). Importance of perceived naturalness for acceptance of food additives and cultured meat. Appetite, 113, 320-326. https://doi.org/http://dx.doi.org/10.1016/j.appet.2017.03.019

Siegrist, M., Sütterlin, B., \& Hartmann, C. (2018). Perceived naturalness and evoked disgust influence acceptance of cultured meat. Meat Science, 139, 213-219. https://doi.org/https://doi.org/10.1016/j.meatsci.2018.02.007

Singer, P. (1981). The Expanding Circle: Ethics, Evolution, and Moral Progress. (P. Singer, Ed.), The Expanding Circle: Ethics, Evolution, and Moral Progress. Princeton, US: Princeton University Press. Retrieved from http://www.jstor.org/stable/j.ctt7sg4n.1

Statista.com. (2015). Median age of the resident population of the United States from 1960 to 2016. Retrieved from https://www.statista.com/statistics/241494/median-age-of-the-uspopulation/

Tucker, C. A. (2014). The significance of sensory appeal for reduced meat consumption. Appetite, 81, 168-179. https://doi.org/10.1016/j.appet.2014.06.022

Tuorila, H., Meiselman, H. L., Bell, R., Cardello, A. V, \& Johnson, W. (1994). Role of Sensory and Cognitive Information in the Enhancement of Certainty and Linking for Novel and Familiar Foods. Appetite, 23(3), 231-246. https://doi.org/10.1006/appe.1994.1056

Verbeke, W., Marcu, A., Rutsaert, P., Gaspar, R., Seibt, B., Fletcher, D., \& Barnett, J. (2015). 'Would you eat cultured meat?': Consumers' reactions and attitude formation in Belgium, Portugal and the United Kingdom. Meat Science, 102, 49-58.

367 Verbeke, W., Sans, P., \& Van Loo, E. J. (2015). Challenges and prospects for consumer acceptance of cultured meat. Journal of Integrative Agriculture, 14(2), 285-294. 

https://doi.org/10.1016/S2095-3119(14)60884-4

370 Walker, P., Rhubart-Berg, P., McKenzie, S., Kelling, K., \& Lawrence, R. S. (2005). Public 371 health implications of meat production and consumption. Public Health Nutr., 8(4), 348$372 \quad 356$. https://doi.org/10.1079/PHN2005727

373 Wilks, M. (2018). Consumer Attitudes and Acceptance of Clean Meat. In Reference Module in $374 \quad$ Food Science (pp. 1-5). Elsevier. https://doi.org/http://dx.doi.org/10.1016/B978-0-08100596-5.21892-1

Wilks, M., \& Phillips, C. J. C. C. J. C. (2017). Attitudes to in vitro meat: A survey of potential consumers in the United States.(Research Article)(Author abstract). PLoS ONE, 12(2), e0171904. https://doi.org/10.1371/journal.pone.0171904

379 Wood, M. J., Douglas, K. M., \& Sutton, R. M. (2012). Dead and Alive: Beliefs in 380 Contradictory Conspiracy Theories. Social Psychological and Personality Science, 3(6), 381 767-773. https://doi.org/10.1177/1948550611434786

382 Wood, M. J., Douglas, K. M., \& Sutton, R. M. (2017). Climate change conspiracy theories. In 383 The Oxford Encyclopedia of Climate Change Communication. Oxford University Press. 